USME, LOS RASTROS DE LA GUERRA

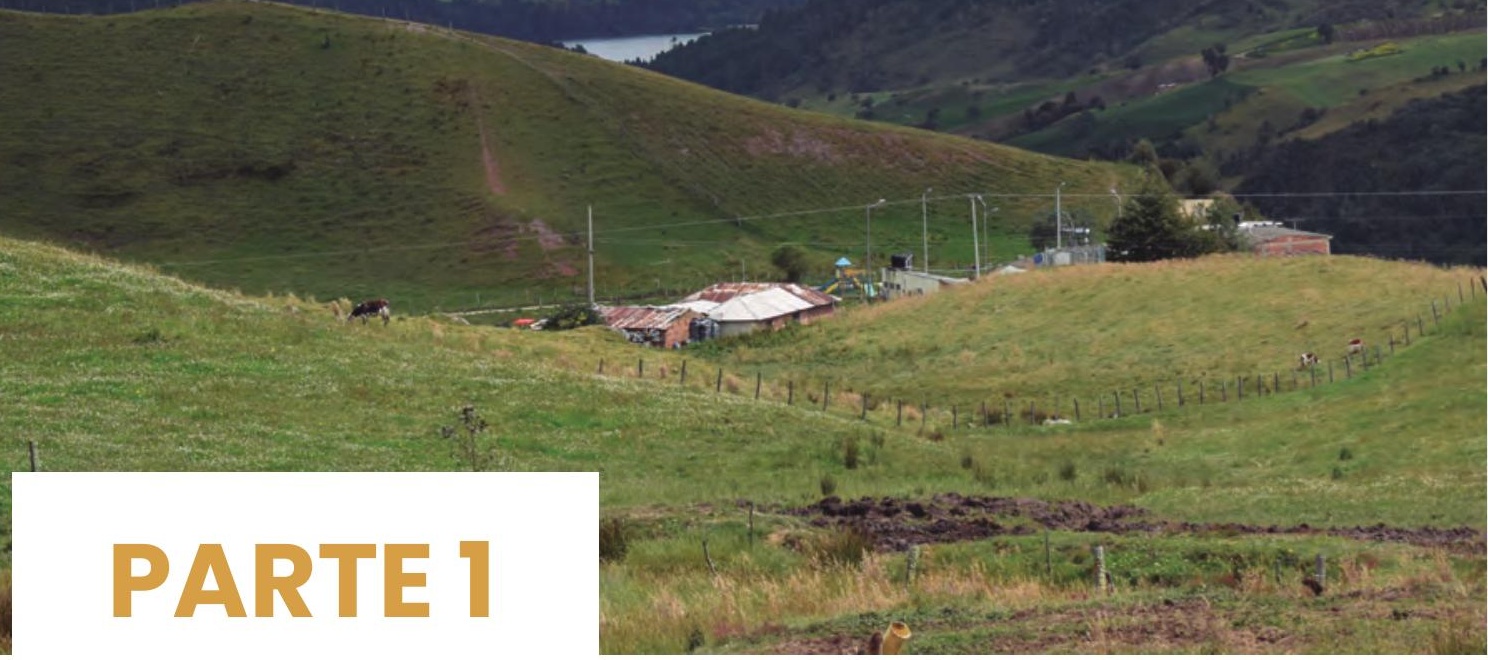

\title{
Esta guerra no es nueva
}



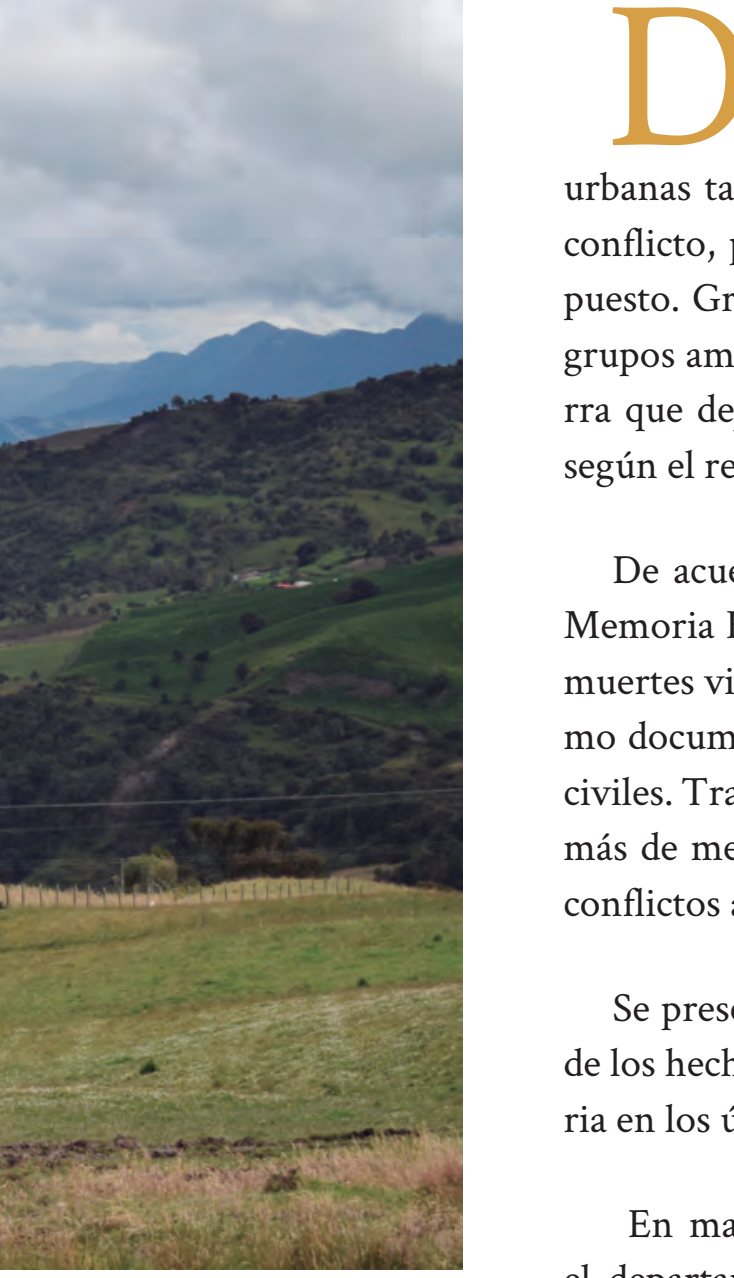

esde la década de los ochenta el conflicto armado colombiano se complejizó en las zonas rurales del país. No obstante, las áreas urbanas también fueron foco de la violencia propia del conflicto, particularmente desde finales del periodo expuesto. Grupos guerrilleros, ejércitos de paramilitares y grupos amados legales fueron protagonistas de una guerra que deja, a la fecha, más de 9 millones de víctimas, según el registro de la Unidad Nacional de Víctimas.

De acuerdo con un informe del Centro Nacional de Memoria Histórica, publicado en 2013, una de cada tres muertes violentas en el país la produce la guerra. El mismo documento indica que el $81 \%$ de estos muertos eran civiles. Tras esas cifras está la historia de un país que lleva más de medio siglo tratando de sobrevivir a uno de los conflictos armados más complejos de América Latina.

Se presenta a continuación un recorrido por algunos de los hechos más relevantes que han marcado esa historia en los últimos 40 años.

En mayo de 1982, en la región del Guayabero, en el departamento del Meta, se llevó a cabo la Séptima Conferencia de las Fuerzas Armadas Revolucionarias de Colombia (FARC). "Fue el momento del salto para las Farc. De ser una guerrilla casi clandestina, sin mayor impacto en el acontecer nacional, comenzó a mojar titulares de prensa", relata el portal Verdad Abierta en un artículo titulado Las conferencias de la expansión, publicado en 2012. 
Una vez finalizada la Séptima Conferencia, el grupo armado cambió su forma de operar: creó más frentes armados, mejoró su estructura económica, ejecutó un plan militar inmediato y articuló las estrategias políticas y financieras, permitiendo el robustecimiento del aparato armado subversivo. "Cambiaron su nombre oficial al de FARC-EP. En esa misma reunión, aprobaron un ambicioso Plan Estratégico que bautizaron con el nombre de Campaña Bolivariana por la Nueva Colombia” (Verdad Abierta, 2012). De este modo, las FARC crearon y aplicaron una estrategia militar en la que establecieron como eje central la Cordillera Oriental.

Un año después de la Séptima Conferencia, el gobierno del presidente Belisario Betancur y las FARC establecieron contacto en búsqueda de una tregua, amparados en la ley de amnistía promulgada en noviembre de 1982 por el Congreso de la República. La ley consistía en liberar de las cárceles del país a muchos de los presos políticos, integrantes de las distintas guerrillas, entre ellos las FARC, el Ejército Popular de Liberación (EPL) y el Movimiento 19 de abril (M-19).

En mayo de 1984 se firmó en Uribe, municipio del Meta, un acuerdo de paz y creación de una comisión de verificación,y en virtud de las negociaciones de paz se dio inicio al cese de hostilidades por parte de las FARC. Así mismo, el 24 de agosto del mismo año, el Gobierno logró acuerdos de tregua con los grupos guerrilleros del EPL y del M-19.

Entre las consecuencias más notorias de este acuerdo, en el que vale la pena indicar que no todos los frentes de las FARC participaron, está la creación de la Unión Patriótica (UP), partido que sufriría de uno de los grandes exterminios que se produjeron en Colombia por parte de fuerzas de extrema derecha. Según Roberto Romero Ospina, entre los años 1985 y 2000 fueron asesinados y desaparecidos 1.598 integrantes de la UP (2012, págs. 25-27).

Solo ese exterminio basta para señalar que los años que siguieron estuvieron marcados por la guerra: muertes, atentados, secuestros, masacres y miedo. Uno de los momentos más emblemáticos del conflicto armado se tejió cruelmente entre el 6 y 7 de noviembre de 1985, cuando se produjo la toma del Palacio de Justicia por parte del M19. 
El comando "Iván Marino Ospina” tomó por asalto el edificio más emblemático de la justicia en el país, ubicado a pocas cuadras de la casa presidencial. El fin era presentar ante el Gobiernouna demanda armada y exigir un juicio público al presidente Belisario Betancur (Maya, 2010).

Posteriormente, el ejército retomó, por medio de la fuerza, el Palacio de Justicia buscando controlar el asalto. No obstante, esa retoma acrecentó la violencia. Según informes oficiales y periodísticos en ese hecho murieron alrededor de 100 personas, 12 de ellas magistrados, incluyendo al presidente de la Corte Suprema, Alfonso Reyes Echandía.

Carlos Medellín Becerra describe lo qué pasó: "Desde el momento mismo de la toma hasta su trágico desenlace 24 horas después, no cesaron los disparos, las bombas, los tanques, las llamas. Por eso el Presidente de la Corte exigió el cese al fuego inmediato ante lo que ya se presagiaba como un Holocausto. El Presidente Betancur, que no quiso pasarle al teléfono, omitió sus deberes constitucionales y dejó que la barbarie y la muerte se instalaran a sus anchas en el Palacio de Justicia. (...). Los magistrados y demás civiles fueron asesinados. Cayeron entre el fuego cruzado de la Fuerza Pública y la guerrilla. Los guerrilleros también murieron. Y los que salieron con vida, como es el caso de la guerrillera Irma Franco, fueron desaparecidos" (Medellín Becerra, 2015, pág. 56)

Este acontecimiento condujo a que la sociedad se empezara a cuestionar la legitimidad de la guerra y del uso de la fuerza como medio para lograr las transformaciones que necesitaba el país. Uno de esos cambios lo empezó a dar el M-19, cinco años después de la toma del Palacio de Justicia.

El 9 de marzo de 1990, después de 16 años de lucha armada, los militantes de esa guerrilla entregaron las armas como un hecho político y simbólico del fin del conflicto armado. El comandante Carlos Pizarro envolvió su pistola en una bandera de Colombia y la colocó sobre una mesa. "Estaban presentes delegados de gobiernos de distintos países de América Latina y de la Internacional Socialista, tres militares, un general venezolano, uno suizo y un experto en balística. Un jefe militar del M-19 había dado la orden: ¡Por Colombia, por la paz, dejad armas! “(V. Grabe, 2010). 
Pero el conflicto no cesó con ese proceso de paz. El Gobierno colombiano -para entonces liderado por César Gaviria- ordenó, el 9 de diciembre de 1990, la Operación Colombia, que tenía como objetivo bombardear la sede del secretariado de las FARC, ubicada en Uribe -Meta-. Según el periódico de El Tiempo del 11 y 12 de diciembre de 1990, el operativo, que movilizó más de 7.000 miembros del ejército, consiguió reducir Casa Verde, el principal campamento de las FARC.

Posterior al ataque, la organización guerrillera respondió con una contraofensiva militar, pero esta vez en las ciudades, en especial Bogotá, la sede del poder político-administrativo del país. De este modo la guerrilla campesina pasó a formar bloques urbanos. Así las FARC estableció en la capital del país el Bloque Antonio Nariño.

Un informe del periódico El Espectador relata que si bien en la Séptima Conferencia, en 1982, las FARC habían decidido entrar a los centros urbanos "la construcción de estructuras clandestinas en ciudades como Bogotá, Cali y Medellín, se definió en la Octava. De acuerdo con el informe de la Fundación Ideas para la Paz, Hoy y ayer del Bloque Oriental de las Farc, los frentes de esta estructura se desplegaron a lo largo de la cordillera oriental, para conectar a Cundinamarca con el Meta, Guaviare y la frontera con Venezuela” (Ávila Cortés \& Castrillón , 2020).

Además de la llegada clandestina de grupos guerrilleros a las ciudades, se sumó el fortalecimiento de los grupos paramilitares desde 1985. Combates entre guerrilleros y paramilitares, asesinatos, masacres y el despojo violento de tierras de campesinos se convirtieron en la cotidianidad nacional.

Esto sería el preámbulo de uno de los periodos más complejos del conflicto armado colombiano: la década de los noventa. “1997 fue una época clave para los paramilitares. En este año, Carlos Castaño logra integrar los diferentes grupos que delinquían en el país constituyendo las Autodefensas Unidas de Colombia. Éstas marcarían una de las épocas más sangrientas de la historia del país, en la que se registrarían más de mil masacres, millones de personas desplazadas por la violencia, la alianza de paramilitares y políticos en las regiones y la expansión del poder paramilitar en todo el país” (Verdad Abierta, 2008). 
En este contexto, a inicios del siglo XXI, con el apoyo de organizaciones locales e internacionales, en el Gobierno de Andrés Pastrana, entre 1998 y el 2002, se estableció un proceso de paz entre las FARC y el Gobierno Nacional. La sede de dichos acuerdos se denominó zona de distensión, conformada por un área de 42.139 kilómetros cuadrados, ubicada entre los municipios de Mesetas, Uribe, Macarena, Vistahermosa y San Vicente del Caguán, en los departamentos del Caquetá y Meta. Nunca hubo cese al fuego bilateral.

Pese a los diversos encuentros que se produjeron entre las partes, al acompañamiento internacional y a la expectativa generada a la opinión pública, el grupo guerrillero continuó perpetrando atentados contra la sociedad civil y la fuerza pública. Por consiguiente, el proceso fue abolido por el presidente el 20 de febrero de 2002, tras el secuestro de Jorge Eduardo Gechem Turbay, a manos de un frente de las FARC (Castellanos Díaz, 2011, pág. 24).

En este contexto, entre los años 2001 y 2003 se intensificó la guerra en las ciudades. Los diversos grupos armados, con el objetivo de estar más cerca al poder y buscando que sus atentados tuvieran mayor repercusión, centraron sus esfuerzos en los frentes urbanos.

El 7 de agosto del 2002, Álvaro Uribe Vélez asumió la presidencia de Colombia. Un par de meses después, con el objetivo de acabar las milicias urbanas de las guerrillas de las FARC, el ELN y los Comandos Armados Populares (CAP) que libraban una guerra en Medellín, ordenó la ejecución de la "Operación Orión" en la comuna 13 de esta ciudad; este era el comienzo de un gobierno que proclamaba la política de "mano dura".

Sandra Milena Álvarez, fundadora de Agroarte colectivo de la Comuna 13 de Medellín, escribió en 070: "En el operativo participaron fuerzas conjuntas del Ejército, el DAS, la Policía, el CTI, la Fiscalía y las fuerzas especiales antiterroristas que durante un mes se tomaron la zona con tanquetas, helicópteros artillados y 1.500 efectivos. El saldo fueron miles de muertos, heridos, desaparecidos y 4 mil desplazados, según el informe del Centro Nacional de Memoria Histórica” (Álvarez , 2019). 
En 2003 Álvaro Uribe emprendió el proceso de desmovilización y desarme de 34 bloques de las Autodefensas Unidas de Colombia en lo que se conoció como el Pacto de Ralito.

Según el Centro Nacional de Memoria Histórica, las desmovilizaciones de las autodefensas iniciaron el 25 de noviembre de 2003, en Medellín, con el bloque Cacique Nutibara, y terminaron el 15 de agosto de 2006 con el bloque Elmer Cárdenas. En 38 actos se desmovilizaron 31.671 integrantes de los grupos paramilitares.

Con las Farc el gobierno implementó una política guerrerista que le permitió dar a la organización guerrillera más fuerte del país los siguientes golpes: rescate de secuestrados a través de estrategias como la Operación Jaque; captura y extradición de figuras clave de la organización como Nayibe Rojas Valderrama, alias Sonia, y Ovidio Ricardo Palmera Pineda, alias Simón Trinidad. Si dio de baja a importantes integrantes del secretariado como: alias Raúl Reyes, el primero de marzo de 2008 en un campamento en la frontera con Ecuador; alias Martín Caballero, el 24 de octubre de 2007; y alias El Negro Acacio el dos de septiembre de 2007.

Tras ocho años de gobierno de Uribe, su ministro de Defensa, Juan Manuel Santos, se lanza a la presidencia, obteniendo la mayoría de los votos, bajo la promesa de continuar con la Política de Seguridad Democrática desarrollada por su predecesor.

En 2011 el nuevo gobierno retoma el concepto de conflicto armado, para referirse a la situación del país, tras años en los que el gobierno de Uribe se negaba a usar ese concepto y en su reemplazo utilizaba la categoría terrorismo, para referirse a los actos de las guerrillas.

El cambio en el lenguaje se produce con el ánimo de impulsar un proyecto de Ley en el que se reconoce a las víctimas y se obliga a todo el aparato estatal a garantizarles reparación. De esa manera nace La Ley de Víctimas 1448 de 2011, en la que se define que se consideran víctimas aquellas personas que individual o colectivamente hayan sufrido un daño por hechos ocurridos a 
partir del $1^{\circ}$. de enero de 1985 , como consecuencia de infracciones al Derecho Internacional Humanitario o de violaciones graves y manifiestas a las normas internacionales de Derechos Humanos, ocurridas con ocasión del conflicto armado interno, tal como reza la ley.

En mayo de 2012 se cumplieron 48 años de enfrentamiento armado entre el Estado colombiano y las FARC-EP. A finales de ese mismo año, el presidente Santos y los representantes de esa guerrilla anunciaron que iniciarían un proceso de diálogos con miras a finalizar el conflicto armado.

Tras cuatro años de negociaciones en la Habana Cuba, el 26 de septiembre de 2016, Juan Manuel Santos, presidente de Colombia, y Rodrigo Londoño, alias "Timochenko", comandante en jefe de las FARC, firmaron el Acuerdo de Paz en Cartagena. La refrendación popular de los acuerdos vía plebiscito, programada para unas semanas después, estaba prevista como el primer paso del cronograma de implementación. Los colombianos fueron llamados a las urnas para responder Sí o No a la pregunta: ¿Apoya el acuerdo final para terminación del conflicto y construcción de una paz estable y duradera? A lo cual, el No supero el Sí por 0,43\% del total de los votos con 62\% de abstencionismo (Botero 2017). A finales de noviembre del mismo año, el gobierno y las FARC refrendaron el Acuerdo de Paz a través del Congreso de la República.

Este paso en la búsqueda de la paz se ha visto enfrentado, en los últimos años, al gobierno de Iván Duque, un aliado de Álvaro Uribe Vélez, que entró cuestionando el Acuerdo y que, según líderes del partido Fuerza Alternativa del Común, conformado por los exintegrantes de las FARC, no ha cumplido con lo estrictamente firmado.

Cuando este libro se terminaba, la sombra del conflicto armado seguía cubriendo gran parte del territorio nacional. Solo el asesinato de líderes sociales y defensores de derechos humanos superaba las 900 víctimas. "Según el último informe del Instituto de estudios para el desarrollo y la paz (Indepaz) desde la firma del Acuerdo con las Farc, entre 2016 y lo corrido del 2020, han asesinado a 840 líderes y 131 líderesas defensores de derechos hu- 
mano" (Martínez, 2020). Entre el 1 de enero de 2020 y el 31 de diciembre del mismo año el portal Verdad Abierta registró 92 masacres en el país, a lo que se suma 249 excombatientes de las Farc, firmantes del acuerdo de paz, asesinados.

Los habitantes de Usme, territorio sobre el que se gesta la historia que este trabajo periodístico recupera, aseguraron al equipo de reporteros de la Unidad de Investigación Periodística, que el Acuerdo de Paz les había creado la ilusión de gozar de su localidad sin miedo. Pero el retorno de algunos de los máximos negociadores de las Farc a las armas, en agosto de 2019, les producía desesperanza. El miedo lo conocen los mayores de la localidad más rural de la capital de Colombia, desde la década del noventa, cuando las Farc encontraron que en ese territorio podían fortalecer el Bloque Antonio Nariño, hacer sentir la guerra en la ciudad, y llegar al poder. 
